\title{
Both Bupivacaine and Levobupivacaine inhibit colon cancer cell growth but not melanoma cells in vitro
}

\author{
Tianci $\mathrm{Li}^{1,2} \cdot$ Lin Chen $^{2} \cdot$ Hailin $\mathrm{Zhao}^{2} \cdot$ Lingzhi Wu$^{2} \cdot$ Joe Masters $^{2} \cdot$ Chongfang Han $^{1} \cdot$ Kazuyoshi Hirota $^{3}$. \\ Daqing $\mathrm{Ma}^{2} \mathbb{D}$
}

Received: 25 April 2018 / Accepted: 13 October 2018 / Published online: 13 November 2018

(c) The Author(s) 2018

\begin{abstract}
Background Retrospective studies indicate that the use of regional anaesthesia causes a reduction in cancer recurrence after oncological surgery, which could be due to anaesthetic's negating effect on immunosuppression related to the surgical stress response. Local anaesthetics may also exert direct suppressive effects on malignant cells, an area where further investigation is urgently needed.

Methods Human colon cancer cells and human melanoma cells were cultured and then treated with $1 \mathrm{mM}$ bupivacaine or levobupivacaine for up to 24 or $48 \mathrm{~h}$. Their migratory ability was measured by scratch assay, proliferation determined with Ki67 immunofluorescence staining, and apoptosis accessed with annexin V and PI staining on flow cytometry. The effects of bupivacaine and levobupivacaine on cellular signaling and molecular response, specifically, on endoplasmic reticulum stress (ERS), were studied with immunostaining and western blot.

Results In colon cancer cells, treatment with bupivacaine and levobupivacaine significantly inhibited cell migration $\left({ }^{* *} p<0.01,{ }^{* *} p<0.001 ; n=4\right)$ and proliferation $(* * p<0.01 ; n=4)$, while increasing the expression of CHOP $(* * * p<0.001$; $n=4)$ and decreased the expression of $\operatorname{Grp} 78\left({ }^{*} p<0.05 ; n=4\right)$. These effects were not mirrored by melanoma cells, such that no significant increase in apoptosis was seen in either melanoma cell lines following treatment.

Conclusion These in vitro data suggested that both bupivacaine and levobupivacaine suppress colorectal adenocarcinoma cell proliferation and migration, which are concurrent with increased endoplasmic reticulum stress. Conversely, melanoma cells are more resilient to these two commonly used local anaesthetics. Further in vivo studies or clinical trials are needed.
\end{abstract}

Keywords Bupivacaine $\cdot$ Levobupivacaine $\cdot$ Colon cancer $\cdot$ Melanoma

\section{Introduction}

Cancer is one of the leading causes of global mortality resulting in 8.2 million deaths worldwide in 2012, with 14 million newly diagnosed cases each year (expected to rise

Daqing Ma

d.ma@imperial.ac.uk

1 Department of Anesthesiology, Shanxi Dayi Hospital, Shanxi Academy of Medical Sciences, Taiyuan, Shanxi, China

2 Anaesthetics, Pain Medicine and Intensive Care, Department of Surgery and Cancer, Faculty of Medicine, Imperial College London, Chelsea and Westminster Hospital, London SW10 9NH, UK

3 Department of Anesthesiology, Hirosaki University Graduate School of Medicine, Hirosaki, Japan to 22 million annually in the next two decades) [1]. However, the specific mechanisms of tumourigenesis have not been completely uncovered, and despite significant advances in the development of targeted cancer therapies, excisional surgery supported by chemotherapy and/or radiotherapy remains the standard treatment for most patients with solid organ tumours. Accordingly, the impact of perioperative management (including anaesthetic drugs) on cancer prognosis following surgery has become an area of great interest [2-5]. Clinical retrospective data indicated that application of local anaesthetics during surgery is related to a lower level of cancer recurrence and metastasis [6,7], and such observation prompts further investigation into the action of local anaesthetics on cancer biology.

Local anaesthetics are used in cancer surgery for local infiltration, peripheral nerve blockade, and central neuraxial anaesthesia as part of the patient's perioperative 
analgesic regimen. Regional anaesthesia is often combined with general anaesthesia to reduce the quantity of opioids and volatile anaesthetic agents required [8]. In addition to this, the techniques of regional anaesthasia appear to have systematic anti-inflammatory effects that can inhibit the recurrence and metastasis of malignant cells by attenuating the immunosuppression associated with the surgical stress response. This immunosuppression inhibits the actions of immunocytes such as natural killer cells [9], which can kill residual tumour cells without deliberate activation, and hence undermines efforts to eradicate the malignancy. Study also indicates a direct inhibitory effect of amide local anaesthetic ropivacaine on cancer cells in vitro [10]. It has been demonstrated that blockade of voltage-gated sodium channels (a principal mechanism by which local anaesthetics block sensory nerve conduction) inhibits invasion of colon cancer cells. Amide local anaesthetics can also inhibit the metastasis of lung cancer cells by tumour necrosis factor- $\alpha$-induced Src-activation and intercellular adhesion molecule-1 phosphorylation, both of which are independent of sodium channel blockade [11]. And recent work from our own group showed that bupivacaine induces apoptosis in ovarian and prostate cell lines [12]. Nevertheless, there is still the need for more research on the specific molecular mechanisms underlying these observations, and for translational evidences to pave ways for clinical randomized controlled trials.

Uncontrolled tumour growth leads to disturbance of the intracellular microenvironment, which significantly impairs the normal function of the endoplasmic reticulum (ER), the central organelle of the intracellular membrane system responsible for the synthesis, folding, modification, and transport of proteins. Dysfunction in proteostasis leads to accumulation of misfolded and unfolded polypeptides in the lumen of the ER, followed by relevant chaperone proteins activating further downstream pathways, which puts the cell under endoplasmic reticulum stress (ERS); this can lead to cell death if ERS goes unchecked. Cancer cells are especially susceptible to ERS because of uncontrolled protein synthesis, nutrient deprivation, and hypoxia following their rapid growth [13]. Further investigation into the role of ERS-related pathways in cancer pathophysiology and therapeutics is therefore warranted, and it has been demonstrated that the amide local anaesthetic lidocaine affects cancer cells through such pathways [14].

This study aims to explore the effects of two widely used amide local anaesthetics, bupivacaine and its S-enantiomer levobupivacaine, on colon cancer cells and melanoma cells. The expression of ERS-associated proteins, CHOP and Grp78, will be studied in treated groups to investigate whether these amide local anaesthetics exert their effects on cancer cells in part through ERS pathways.

\section{Materials and methods}

\section{Cell culture}

The human colorectal adenocarcinoma cell line Caco-2 and the human melanoma cell line A375 was purchased from Public Health England (Salisbury, UK). The culture medium used in this research was supplied by Gibco® RPMI 1640 (+ L-Glutamine, Life Technologies, Paisley, UK), 10\% fetal bovine serum (FBS) (Fischer Scientific, Leicestershire, UK) and 1\% Penicillin-Streptomycin (Sigma-Aldrich, Dorset, UK).

\section{Cell seeding in petri dishes}

Cells prepared for experiments were cultured in $60 \mathrm{~mm}$ Petri dishes (Thermo Scientific) with density of $8 \times 10^{5}$ cells $/ \mathrm{mL}$ in $3 \mathrm{ml}$ of medium per dish. Cell number was calculated with a hemocytometer (Hawksley, Lancing, USA) before seeding.

\section{Local anaesthetic treatment}

Bupivacaine hydrochloride isotonic solution (Marcaine, $0.5 \% \mathrm{w} / \mathrm{v}$, AstraZeneca, Luton, UK) and levobupivacaine hydrochloride isotonic solution (Chirocaine, $0.5 \% \mathrm{w} / \mathrm{v}$, AstraZeneca, Luton, UK) were diluted with culture medium separately to reach the concentration of $1 \mathrm{mM}$, while Dulbecco's phosphate buffered saline (DPBS/Modified $1 \times$, Thermo Scientific, Utah, South Logan, USA) was added into culture medium at the same proportion as vehicle control. They were applied when cells grew to $90 \%$ confluence and their effects were determined with annexin $\mathrm{V}$ staining assay, immunostaining, and Western blotting.

\section{Scratch assay}

The scratch assay was performed to assess the migration ability of cancer cells. After cells reach confluence in Petri dishes, horizontal and vertical cross lines were scratched on the cell monolayer by a p1000 plastic micropipette tip. Distance between the "cell-free" gap was almost identical. The previous culture medium was aspirated out and replaced with prepared medicine and control medium after gently washing the cell surface with culture medium to remove cellular debris. Snapping images of scratch area was taken with a microscope assisted with the digital camera (Olympus CK30, Tokyo, Japan) in the same frame and fields at $0 \mathrm{~h}, 24 \mathrm{~h}$, and $48 \mathrm{~h}$. Images were analysed by 
ImageJ software (National Institutes of Health, Bethesda, $\mathrm{MD)}$ to compare the mean percentage of closure area among groups.

\section{Flow cytometry}

To assess the apoptosis of cancer cells, annexin $\mathrm{V}$ and propidium iodide (PI) staining assay was performed. After $24 \mathrm{~h}$ of treatment or control, adhesive cells were harvested through detachment by $0.25 \%$ trypsin and centrifugation at $1400 \mathrm{rcf}$ for $10 \mathrm{~min}$. After resuspending cells with $1 \times$ Binding Buffer, $5 \mu$ of fluorochrome-conjugated annexin $\mathrm{V}$ (Sigma-Aldrich, Saint Louis, USA) was added into $100 \mu \mathrm{l}$ of cell suspension to stain intracellular phosphatidylserine (PS). Incubation was performed in dark under room temperature. $5 \mu$ of propidium iodide staining solution (SigmaAldrich, Saint Louis, USA) was added into $100 \mu$ of cell suspension. Flow cytometry (FACS Calibur, Becton Dickinson, Sunnyvale, CA, USA) was used to detect the percentage of apoptotic cells by FlowJo software (Treestar, Ashland, USA).

\section{Immunofluorescence}

Cells treated with local anaesthetics for $24 \mathrm{~h}$ together with controls were fixed with $4 \%$ paraformaldehyde and blocked with 3\% donkey serum [15] (Millipore, UK). Cells were incubated at $4{ }^{\circ} \mathrm{C}$ overnight in $3 \%$ DS $0.03 \%$ Triton-X phosphate buffered saline (PBST) with the following primary antibodies: anti-Grp78 (H-129) (1:200, rabbit polyclonal antibody; Santa Cruz Biotechnology, UK) to detect the general transducer of ERS Grp78, anti-GADD153 (F-168) (1:200, rabbit polyclonal antibody; Santa Cruz Biotechnology, UK) to detect the expression of CHOP, and anti-KI67 to visualize nuclear expression of Ki67 (1:200, monoclonal mouse antibody; DakoCytomation, Produktionsvej, Denmark) to determinate the proliferative state of cancer cells.

On the second day, cells were incubated in the corresponding secondary antibodies: fluorescein isothiocyanate (FITC)-conjugated donkey anti-rabbit IgG 1:200; Millipore, or FITC-conjugated donkey anti-mouse IgG (1:200; Millipore), and mounted with DAPI (Vector Laboratories). Cells were examined with a Nikon E1000M (Nikon, Surrey, UK) fluorescence microscope under $20 \times$ objective. Images were snapped with the identical exposure settings.

\section{Western Blot}

Cells were lysed with cell lysis buffer (Cell-Signaling Technology), and the extracted protein fraction was quantified by Bradford protein assay (Bio-Rad laboratories, Hercules, CA, USA) to ensure equal loading of $50 \mu \mathrm{g}$ of protein for each sample. Samples were loaded into NuPAGE® 4\%-12\%
Bis-Tris Precast Gels (Thermo Scientific, UK) for electrophoresis. Protein bands were transferred from gel onto polyvinylidenedifluoride (PVDF) membranes, and incubated with primary antibodies-Grp78, GADD153 or cleaved caspase-3 p17 (H-60) (rabbit polyclonal antibody; Santa Cruz Biotechnology, UK) at dilution factor of 1:300. On the second day, membranes were incubated with secondary antibody (anti-rabbit HRP conjugated, Cell-Signaling Technology) for $1 \mathrm{~h}$ at room temperature at dilution factor of 1:1000, before development with enhanced chemiluminescence (ECL) system (Santa Cruz, Dallas, TX, USA). Protein bands were visualized by Syngene GeneSnap software (Syngene, Cambridge, UK). The intensity of grey scale of protein bands was assessed with ImageJ.

\section{Statistical analysis}

Statistical analysis of all data was processed by GraphPad Prism version 5 (La Jolla, CA). The comparison between different groups was tested by one-way ANOVA and posthoc Tukey test in Western blotting and immunofluorescence. Scratch assay was analysed by two-way ANOVA. Values were presented as mean \pm Standard Deviation (SD), and a $p$ value (two-tailed) $<0.05$ was considered to be statistically significant.

\section{Results}

\section{Bupivacaine and levobupivacaine inhibited the migration ability of Caco2 cells but not $\mathrm{A} 375$ cells}

As shown by the scratch assay, treatment with $1 \mathrm{mM}$ bupivacaine or $1 \mathrm{mM}$ levobupivacaine for $24 \mathrm{~h}$ and $48 \mathrm{~h}$ significantly decreased the gap closure rate of Caco2 cells (Fig. 1, b). Yet there was no significant difference in gap closure and migration ability following bupivacaine or levobupivacaine treatment in A375 cell line (Fig. 1c, d).

\section{Bupivacaine and levobupivacaine did not induce apoptosis in both cell lines but arrested the cell cycle of the Caco2 cell line}

Given that the application of the local anaesthetics affected cell healing, immunofluorescence staining was performed to evaluate tumour proliferation state. The mitosis marker, Ki-67 protein, which only exists in cells in the G1-M phases of cell cycle, but not in resting or damaged cells, was chosen as the proliferation marker. Bupivacaine and levobupivacaine significantly reduced the number of Caco- 2 cells showing positive Ki67 nuclear staining, suggesting that both agents significantly inhibited cell proliferation in this cell 

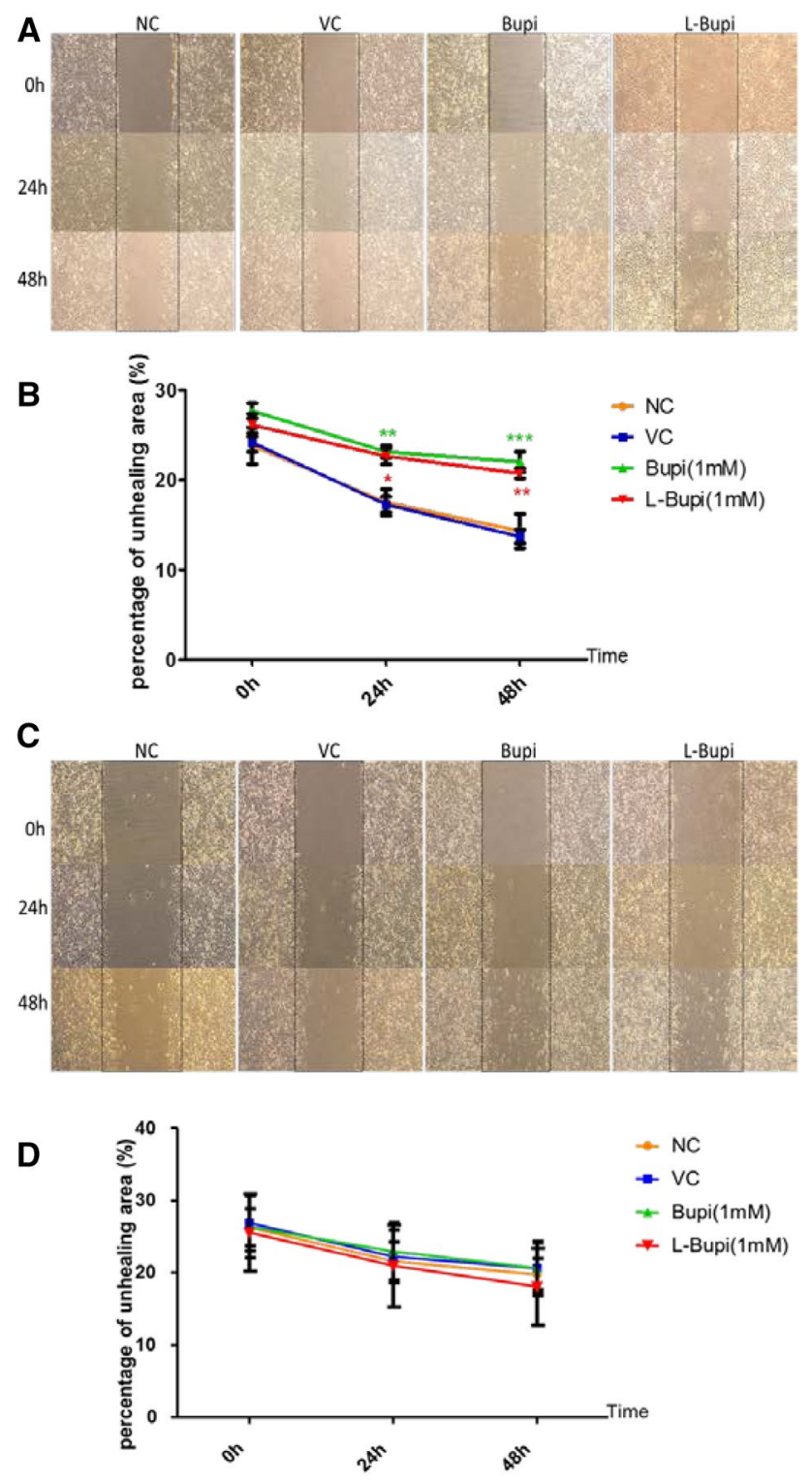

Fig. 1 The effect of bupivacaine and levobupivacaine on migration ability of Caco2 cells and A375 cells. Representative microphotographs showing the scratch healing state after $24 \mathrm{~h}$ and $48 \mathrm{~h}$ of bupivacaine or levobupivacaine treatment in (a) caco-2 cells and A375 cells (c). Every image of scratch assay was taken under $\times 20$ objective. b, d Illustrate the changes in percentage of unhealed area of caco-2 cells and A375 cells overtime. (data shown as mean \pm SD; $n=4 ; * p<0.05, * * p<0.01, * * * p<0.001 ; N C$ naïve control, $V C$ vehicle control, Bupi application of $1 \mathrm{mM}$ bupivacaine, L-Bupi application of $1 \mathrm{mM}$ levobupivacaine)

line (Fig. 2e, f); on the other hand, both agents showed no significant effect on the nuclear level of Ki67 of A375 cells and their proliferation (Fig. 2g, h).

Annexin V and propidium iodide (PI) staining assays were performed to examine the apoptotic states of the Caco2 cells and A375 cells. Annexin V binds to phosphotidylserine (PS) when it translocates to the extracellular side of the

cell membrane during the early stage of apoptosis. PI binds to DNA but is cell membrane-impermeable, such that it is excluded from viable cells until the late stages of apoptosis. The percentage of apoptotic cells in Caco2 cells and A375 cells remained at very low level $(<1 \%)$ following drug treatment and there was no significant difference across groups (Fig. 2c, d).

\section{Bupivacaine and levobupivacaine decreased the expression of Grp78 and increased the expression of CHOP in $\mathrm{CacO} 2$ cell line but not in $\mathrm{A} 375$ cell line}

As the general transducer of ERS, Grp78 was detected by western blotting and immunofluorescence in the two cell lines after $24 \mathrm{~h}$ of treatment with $1 \mathrm{mM}$ bupivacaine or $1 \mathrm{mM}$ levobupivacaine.

In Caco2 cells, western blot testing showed no significant difference between all test groups (Fig. 3a), but immunofluorescent analysis demonstrated a reduction in Grp78 level in the bupivacaine or levobupivacaine treatment groups $(p<0.05$; Fig. $3 c)$. It is also evident from the immunofluorescence images that Grp78 was activated and localised into the nuclei, an observation that is consistent with its role as a heat-shock protein (Fig. 3b). In A375 cells, the expression of Grp78 was not significantly altered following drug treatment, when evaluated with either westernblot analysis or immunofluorescent staining(Fig. 3d-f).

The application of $1 \mathrm{mM}$ bupivacaine or $1 \mathrm{mM}$ levobupivacaine for $24 \mathrm{~h}$ induced a significant increase in CHOP protein in Caco 2 cells, as seen with both western blot analysis and immunofluorescence $(p<0.05$; Fig. $4 \mathrm{a}-\mathrm{c})$. The immunofluorescent images demonstrated an increase in the nuclear localisation of CHOP after drug treatment (Fig. 4b). The A375 cell line showed no significant difference in CHOP expression after drug treatment (Fig. 4d-f).

\section{Discussion}

Our results demonstrate that bupivacaine or levobupivacaine causes significant inhibition in cell migration ability and cell cycle arrest in the colorectal cancer Caco- 2 cell line. Concurrent with such changes in cancer behavior are changes in the expression of the ERS proteins, to suggest that the antimigratory and anti-proliferative effects of local anaesthetics on colon cancer cell may be mediated through endoplasmic reticulum stress; and the lack of ERS response in melanoma cells following local anaesthetics treatment may also explain their unchanged migration and proliferation behaviors.

In this study, after treatment of $1 \mathrm{mM}$ bupivacaine and levobupivacaine for $24 \mathrm{~h}$, the percentage of Ki67 + cells significantly decreased in the Caco-2 cell, without significant 
Fig. 2 State of apoptosis and proliferation in Caco2 cells and $\mathrm{A} 375$ cells after treatment of bupivacaine and levobupivacaine. Each of the two cell lines was treated with $1 \mathrm{mM}$ bupivacaine or levobupivacaine for $24 \mathrm{~h}$. Cell distribution diagrams with PI and annexin $\mathrm{V}$ staining are shown for $\mathbf{a}$ Caco2 and b A375. Percentages of apoptotic $\mathrm{Caco} 2$ cells (c) and A375 cells (d) $(n=4)$. Representative immunofluorescence images of $\mathrm{Ki}-67$ in Caco2 cells (e) and A375 cells (g) ( $\times 20$ magnification; nuclei counterstained with DAPI; scale bar $=50 \mu \mathrm{m}$ ). Bar chart showing and comparing percentages of Ki67 + cells across different treatment groups in $\mathrm{Caco} 2$ cells (f) and A375 cells (h). $(n=3)$ (Results are mean $\pm \mathrm{SD}$; ${ }^{*} p<0.05 ; * * p<0.01 ; N C$ naïve control, $V C$ vehicle control, Bupi $24 \mathrm{~h}$ treatment of $1 \mathrm{mM}$ Bupivacaine, L-Bupi $24 \mathrm{~h}$ treatment of $1 \mathrm{mM}$ Levobupivacaine)

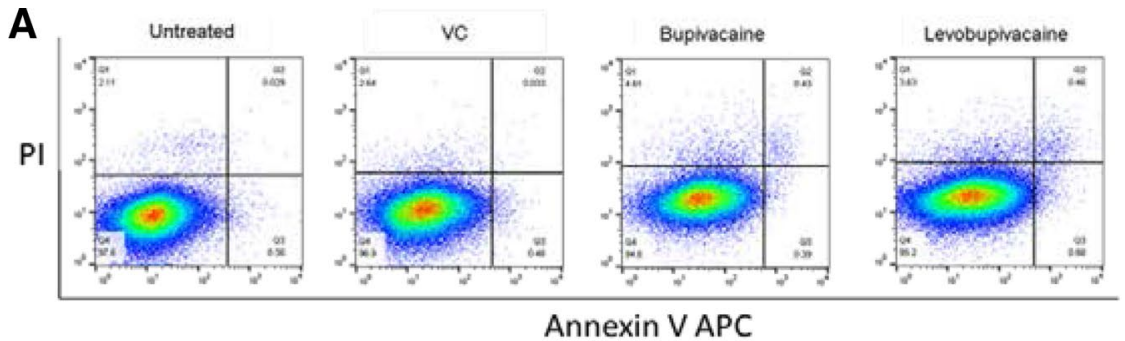

Annexin V APC

B

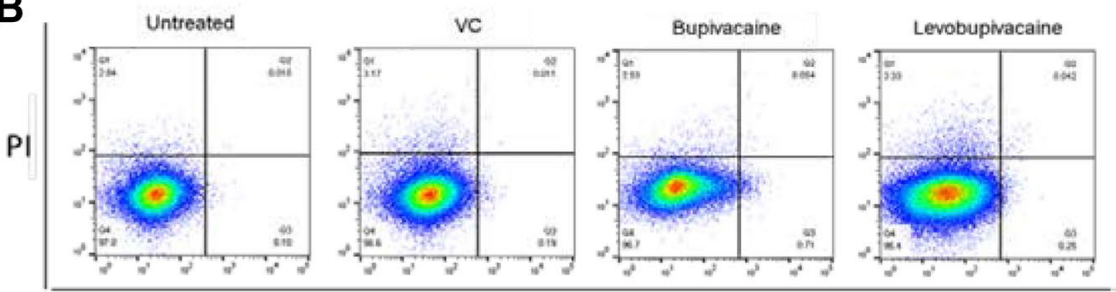

Annexin V APC
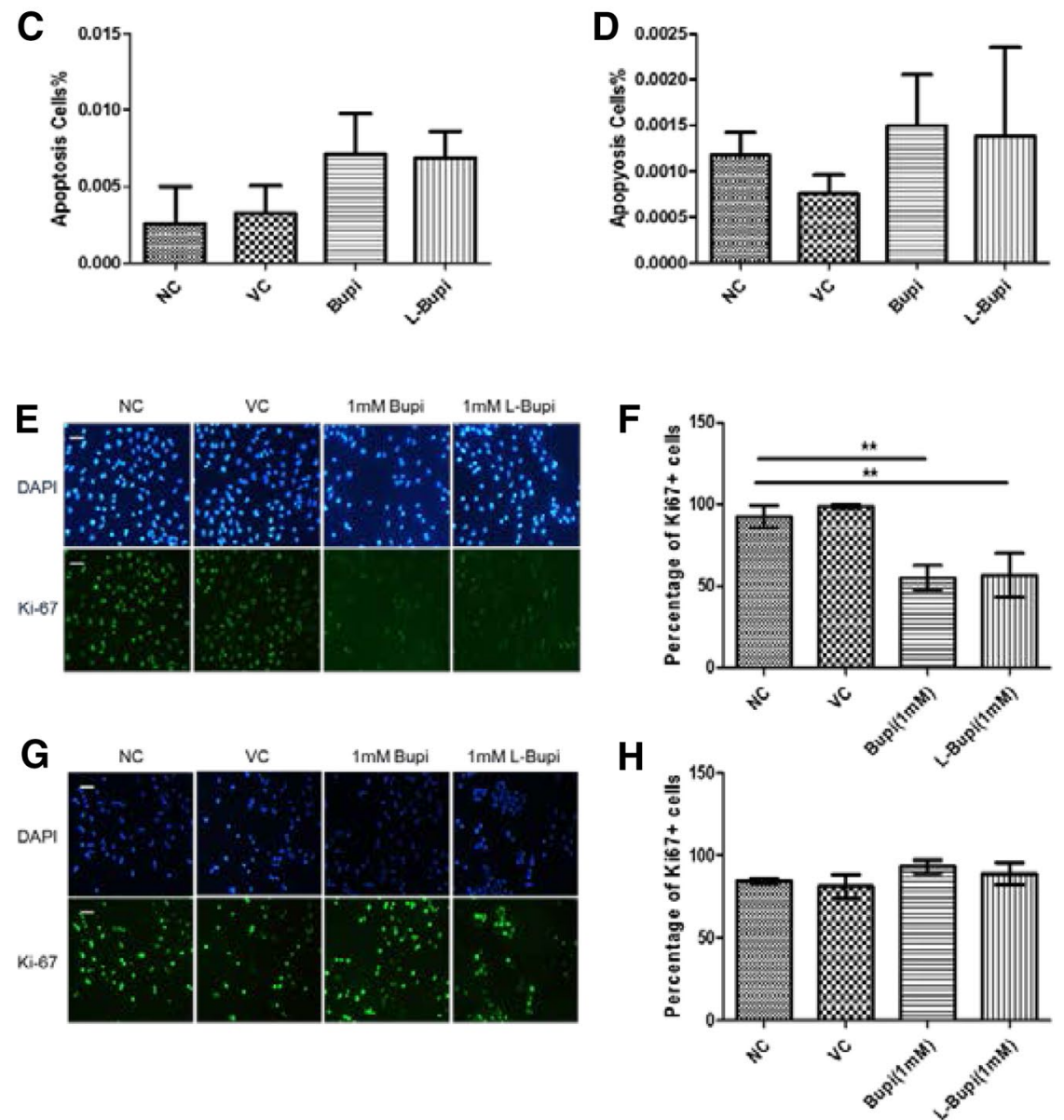

increase in apoptosis. Previous studies have also indicated that both bupivacaine and levobupivacaine can inhibit the proliferation of cancer cells without inducing cell death [16].

Heat shock proteins exist in the lumen of endoplasmic reticulum and many members of this family act as chaperones to facilitate protein folding. Of this group, the $78 \mathrm{kDa}$ glucose-regulated protein (Grp78) is one of the most important regulators of ERS. Grp78 combines with hydrophobic residues of immature proteins for subsequent processing. When under normal condition, Grp78 can deactivate three important sensors of ERS-PKR-like endoplasmic reticulum kinase (PERK), inositol-requiring 
A
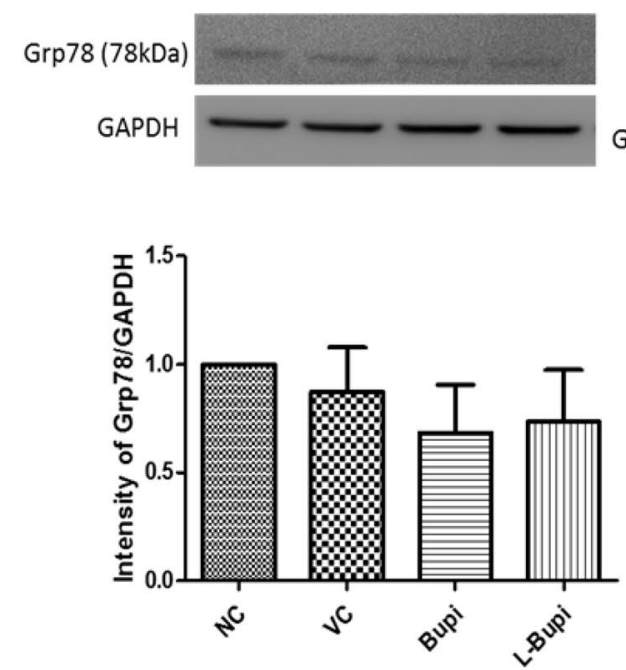

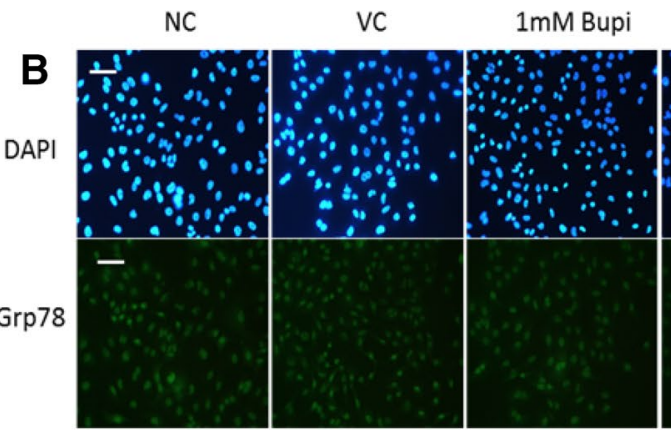

C

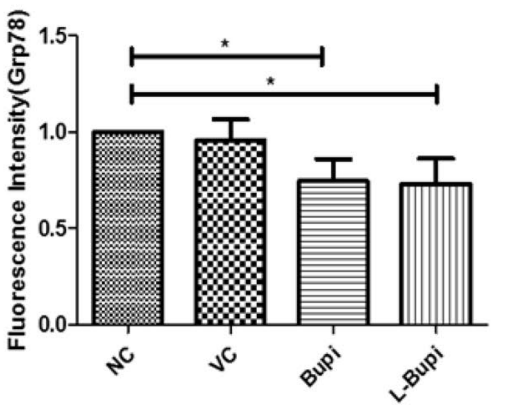

$\mathbf{E}$

DAPI

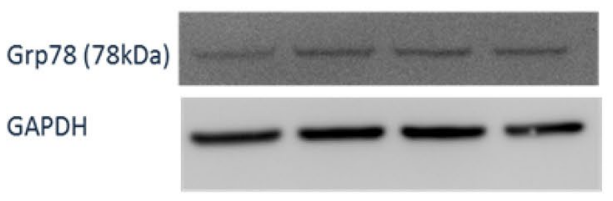

Grp78

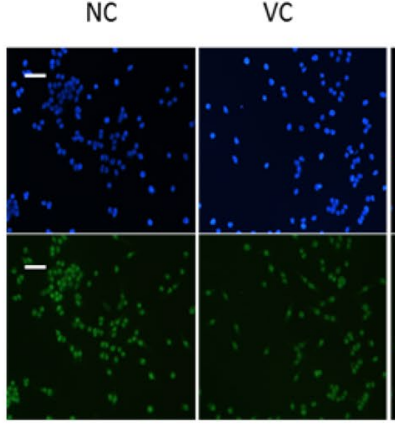

$1 \mathrm{mM}$ Bupi

$1 \mathrm{mM} \mathrm{L-Bupi}$
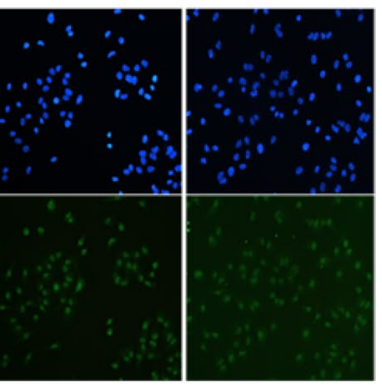

Fig. 3 Expression of Grp78 after application of bupivacaine and levobupivacaine. Representative western blots and band density analysis of Grp78 in a Caco2 cells and d A375 cells. Grey scale of intensity values expressed as ratio relative to GAPDH. Representative immunofluorescence images of Grp78 in b Caco2 cells and e A375 cells ( $\times 20$ magnification; nuclei counterstained with DAPI; scale bar

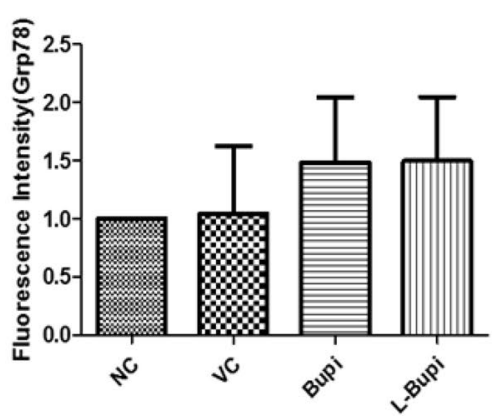

$=50 \mu \mathrm{m})$. Immunofluorescence intensity of Grp78 in (C) Caco-2 cells and (F) A375 across different treatment groups $(n=4$, data shown as mean $\pm \mathrm{SD} ;{ }^{*} p<0.05 ; N C$ naïve control, $V C$ vehicle control, Bupi $24 \mathrm{~h}$ treatment of $1 \mathrm{mM}$ Bupivacaine, L-Bupi $24 \mathrm{~h}$ treatment of $1 \mathrm{mM}$ Levobupivacaine)

the dissociation of Grp78 from PERK, IRE1, and ATF6 will "dis-inhibit" the downstream ERS signaling pathways. This ERS response, also known as the unfolded protein response (UPR) [18], is a homeostatic mechanism that can 

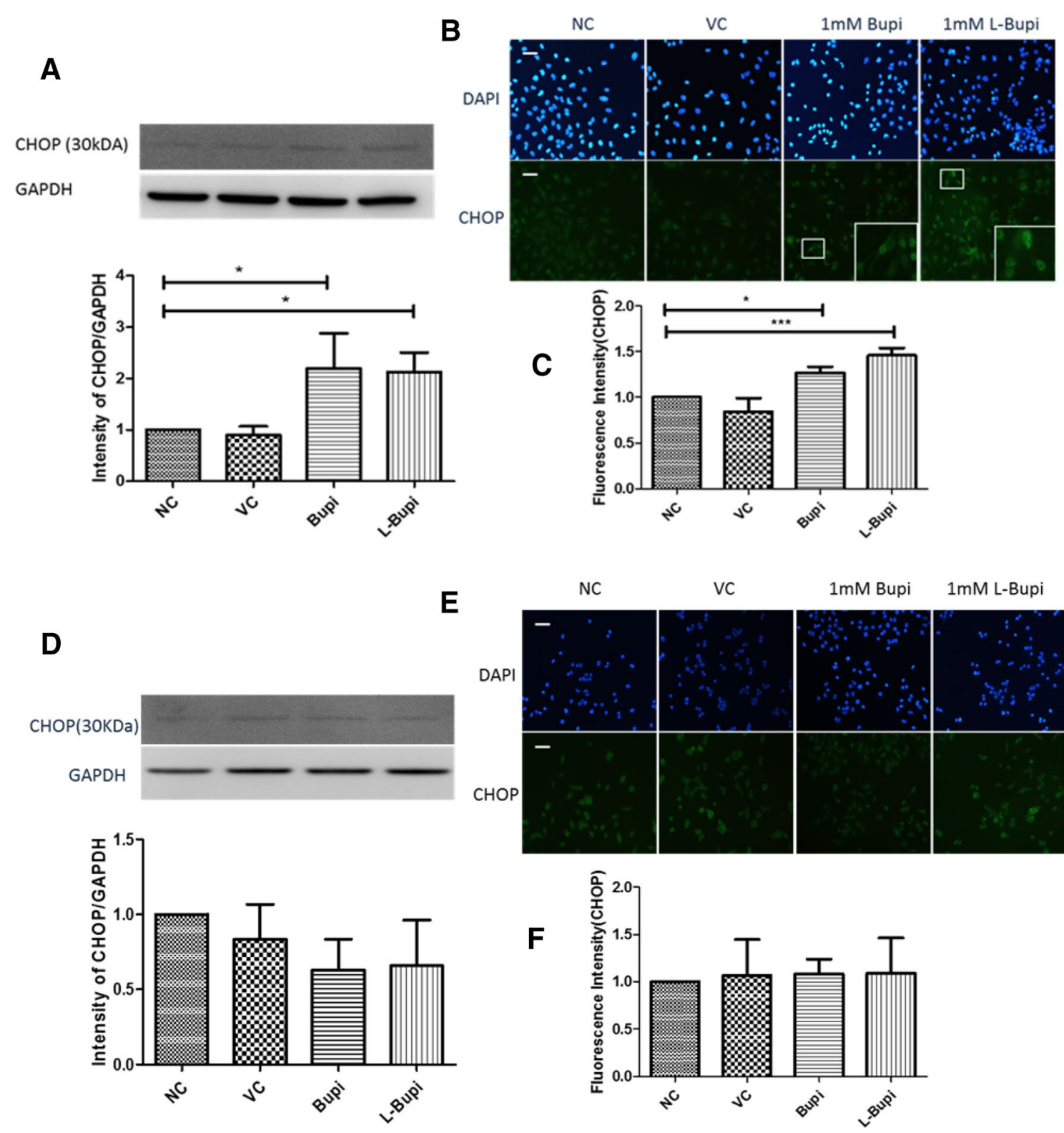

E

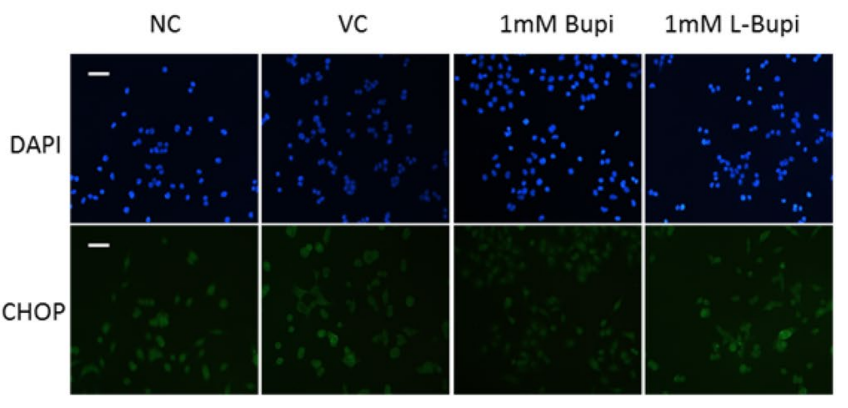

C
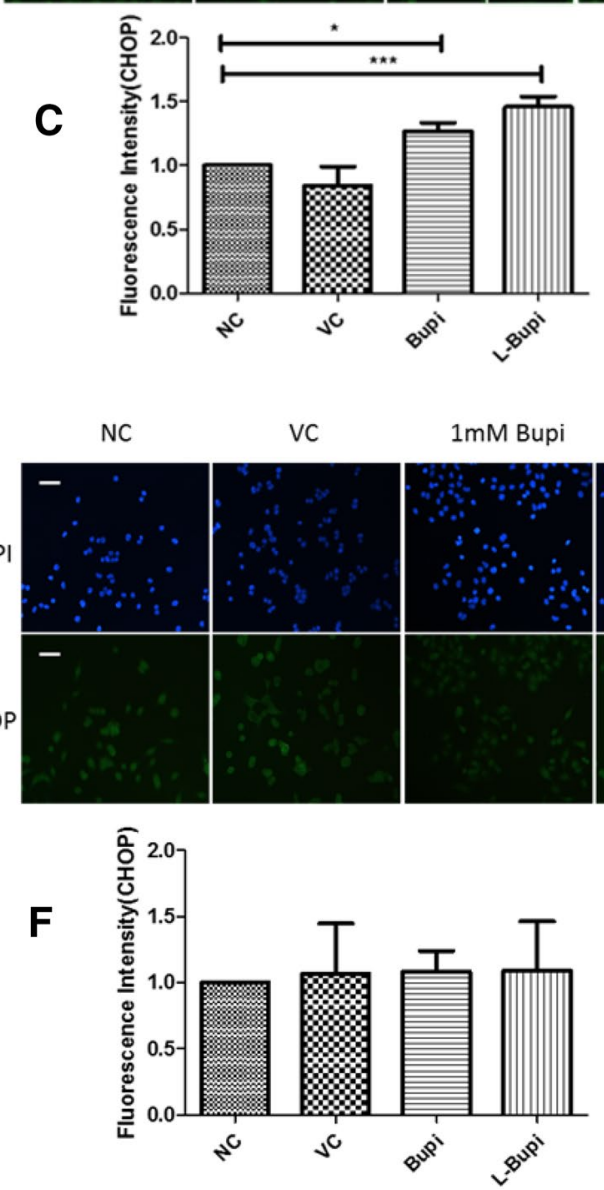

Fig. 4 Expression of CHOP after application of bupivacaine and levobupivacaine. Representative western blots and band density analysis of CHOP in a Caco 2 cells and d A375 cells. Grey scale of intensity values expressed as ratio relative to GAPDH. Representative immunofluorescence images of CHOP in b Caco- 2 cells and e A375 cells ( $\times 20$ magnification; nuclei counterstained with DAPI; scale bar

$=50 \mu \mathrm{m})$. Immunofluorescence intensity of CHOP in $\mathbf{c}$ Caco- 2 cells and $\mathbf{f}$ A 375 cells across different treatment groups $(n=4$, data shown as mean $\pm \mathrm{SD} ;{ }^{*} p<0.05 ; N C$ naïve control, $V C$ vehicle control, Bupi $24 \mathrm{~h}$ treatment of $1 \mathrm{mM}$ Bupivacaine, L-Bupi $24 \mathrm{~h}$ treatment of $1 \mathrm{mM}$ Levobupivacaine)

exert either a cytoprotective effect, or induce apoptosis depending on the severity and duration of stress.

In cancer cells, it is possible that activation of ERS mechanisms could promote cell survival, at least during the initial phase. Following dissociation of Grp78, PERK-eIF2 $\alpha$ (phosphorylate eukaryotic initiation factor $2 \alpha$ ) axis is activated and suppresses polypeptide synthesis through translational attenuation to prevent further accumulation of misfolded proteins within the ER, and thus relieving the cancer cells

from intracellular stress to favor cancer survival [19]. Likewise, the activation of other ERS signal transducers, IRE1 and ATF6, can also favor tumour growth and enhance cell tolerance to stress by activating the mRNA of transcription factor X-box-binding protein 1 (XBP-1) and upregulating expression of major ER chaperones (including Grp78) and ERAD components [20,21].

On the other hand, with ongoing disruption of ER homeostasis, the aforementioned UPR mechanisms will 
start to downregulate efforts in resisting ERS, while strengthening their tendency to induce cell cycle arrest or programmed cell death [22]. The PERK-eIF2 $\alpha$ pathway is the leading promoter of the transcription factor C/EBP homologous protein (CHOP) [23], which upregulates a range of proteins that drive apoptosis (including growtharrest and DNA-damage inducible protein 34 [GADD34], ER oxidase $1 \alpha$ [ERO1 $\alpha$ ], BCL2-like 11, tribbles-related protein 3 [TRB3], and death receptor 5 [DR5]) and downregulates anti-apoptotic factors (such as BCL-2) [24, 25]. In view of the above, our collective findings that treatment of $\mathrm{Caco} 2$ cells with bupivacaine and levobupivacaine is associated with a decrease in the expression of Grp78 and an increase in the expression of CHOP suggests that these amide local anaesthetics can enhance ERS. Such enhancement in ERS may contribute to local anaesthetics' inhibitory effect on cell migration and proliferation. Interestingly, in some retrospective clinical studies, Grp78 and CHOP seem to play opposing roles in ERS in informing the prognosis of cancer patients. Matsuo et al. collected samples of both uterus and visceral adipose tissue from endometrial cancer patients and found that a more advanced stage and deeper invasion were associated with higher expression of Grp78 [26]. Another study demonstrated that in breast cancer patients, high expression of CHOP correlated with longer survival and a lower recurrence rate [27].

Furthermore, it is worth mentioning that local anaesthetics have wide range of uses in clinical practice and their plasma concentrations can vary widely. In this regard, although the concentration of bupivacaine and levobupivacaine used in the present study $(1 \mathrm{mM})$ far exceeds the plasma concentrations of bupivacaine and levobupivacaine in abdominal wall block, with mean peak plasma concentrations ranging between 1 and $3 \mu \mathrm{M}[28,29]$, local anaesthetics are also administered to patients through intraperitoneal instillation during surgery and/or for post-operative pain relief, and it was found such administration can reduce systemic cytokine and cortisol levels [30, 31]. One can argue that different routes of administration makes it highly plausible for the local anaesthetics to reach tumour removal sites at greater concentrations, for example, after colorectal cancer excision, direct infiltration of local anaesthetics are used clinically and its concentration can reach a considerable level locally, and even higher when administered topically. Nevertheless, as the nature of a proof of concept study of its kind, our data showed that the two local anaesthetics tested in our study did not enhance cancer malignancy and the implication is that they may be favorable for cancer patient use during anaesthesia for surgery. Taken together, one may speculate that the local anaesthetics may prevent local cancer recurrence by suppressing proliferation of cancer cells that have been mobilized and scattered during tumour resection; nonetheless, further time- and concentration-dependent studies are needed to support such hypothesis.

In conclusion, we have demonstrated a direct inhibitory effect of bupivacaine and levobupivacaine on colon cancer cell migration and proliferation, which are associated with increased endoplasmic reticulum stress. In contrast, these observations were not made in the melanoma cell line studied. These findings may indicate elevated ERS as a candidate mechanism for anaesthetics to exert anti-tumour effect; however, further mechanistic studies are warranted before concluding such causal relationship. Ultimately, this work could lead to clinical studies examining the "anti-cancer" characteristics of amide local anaesthetics to further benefit cancer patient care.

Acknowledgements This work is supported by departmental funding.

\section{Compliance with ethical standards}

Conflict of interest All authors declare no conflict of interests.

Open Access This article is distributed under the terms of the Creative Commons Attribution 4.0 International License (http://creativeco mmons.org/licenses/by/4.0/), which permits unrestricted use, distribution, and reproduction in any medium, provided you give appropriate credit to the original author(s) and the source, provide a link to the Creative Commons license, and indicate if changes were made.

\section{References}

1. Forman D, Ferlay J. The global and regional burden of cancer. In: Stewart B, Wild CP, editors. World cancer report. Lyon: International Agency for Research on Cancer; 2014. pp. 16-53.

2. Benzonana LL, Perry NJ, Watts HR, Yang B, Perry IA, Coombes C, Takata M, Ma D. Isoflurane, a commonly used volatile anesthetic, enhances renal cancer growth and malignant potential via the hypoxia-inducible factor cellular signaling pathway in vitro. Anesthesiology. 2013;119:593-605.

3. Huang H, Benzonana LL, Zhao H, Watts HR, Perry NJ, Bevan C, Brown R, Ma D. Prostate cancer cell malignancy via modulation of HIF-1alpha pathway with isoflurane and propofol alone and in combination. Br J Cancer. 2014;111:1338-49.

4. Ciechanowicz SJ, Ma D. Anaesthesia for oncological surgery-can it really influence cancer recurrence? Anaesthesia. 2016;71:127-31.

5. Iwasaki M, Zhao H, Jaffer T, Unwith S, Benzonana L, Lian Q, Sakamoto A, Ma D. Volatile anaesthetics enhance the metastasis related cellular signalling including CXCR2 of ovarian cancer cells. Oncotarget. 2016;7:26042-56.

6. Exadaktylos AK, Buggy DJ, Moriarty DC, Mascha E, Sessler DI. Can anesthetic technique for primary breast cancer surgery affect recurrence or metastasis? Anesthesiology. 2006;105:660-4.

7. Biki B, Mascha E, Moriarty DC, Fitzpatrick JM, Sessler DI, Buggy DJ. Anesthetic technique for radical prostatectomy surgery affects cancer recurrence: a retrospective analysis. Anesthesiology. 2008;109:180-7.

8. Sessler DI, Ben-Eliyahu S, Mascha EJ, Parat MO, Buggy DJ. Can regional analgesia reduce the risk of recurrence after breast 
cancer? Methodology of a multicenter randomized trial. Contemp Clin Trials. 2008;29:517-26.

9. Wada H, Seki S, Takahashi T, Kawarabayashi N, Higuchi H, Habu Y, Sugahara S, Kazama T. Combined spinal and general anesthesia attenuates liver metastasis by preserving TH1/TH2 cytokine balance. Anesthesiology. 2007;106:499-506.

10. Baptista-Hon DT, Robertson FM, Robertson GB, Owen SJ, Rogers GW, Lydon EL, Lee NH, Hales TG. Potent inhibition by ropivacaine of metastatic colon cancer SW620 cell invasion and NaV1.5 channel function. Br J Anaesth. 2014;113(Suppl 1):i39-48.

11. Piegeler T, Votta-Velis EG, Liu G, Place AT, Schwartz DE, BeckSchimmer B, Minshall RD, Borgeat A. Antimetastatic potential of amide-linked local anesthetics: inhibition of lung adenocarcinoma cell migration and inflammatory Src signaling independent of sodium channel blockade. Anesthesiology. 2012;117:548-59.

12. Xuan W, Zhao H, Hankin J, Chen L, Yao S, Ma D. Local anesthetic bupivacaine induced ovarian and prostate cancer apoptotic cell death and underlying mechanisms in vitro. Sci Rep. 2016;6:26277.

13. Clarke HJ, Chambers JE, Liniker E, Marciniak SJ. Endoplasmic reticulum stress in malignancy. Cancer Cell. 2014;25:563-73.

14. Hong DY, Kwon K, Lee KR, Choi YJ, Goo TW, Yu K, Kim $\mathrm{SW}$, Kwon OY. Lidocaine induces endoplasmic reticulum stress-associated apoptosis in vitro and in vivo. Int J Mol Sci. 2011;12:7652-61.

15. Bundscherer A, Malsy M, Gebhardt K, Metterlein T, Plank C, Wiese $\mathrm{CH}$, Gruber M, Graf BM. Effects of ropivacaine, bupivacaine and sufentanil in colon and pancreatic cancer cells in vitro. Pharmacol Res 2015; 95-96:126-31.

16. Jose C, Bellance N, Chatelain EH, Benard G, Nouette-Gaulain $\mathrm{K}$, Rossignol R. Antiproliferative activity of levobupivacaine and aminoimidazole carboxamide ribonucleotide on human cancer cells of variable bioenergetic profile. Mitochondrion. 2012;12:100-9.

17. Pfaffenbach KT, Lee AS. The critical role of GRP78 in physiologic and pathologic stress. Curr Opin Cell Biol. 2011;23:150-6.

18. Walter P, Ron D. The unfolded protein response: from stress pathway to homeostatic regulation. Science. 2011;334:1081-6.

19. Mendez AS, Alfaro J, Morales-Soto MA, Dar AC, McCullagh E, Gotthardt K, Li H, Acosta-Alvear D, Sidrauski C, Korennykh AV, Bernales S, Shokat KM, Walter P. Endoplasmic reticulum stressindependent activation of unfolded protein response kinases by a small molecule ATP-mimic. Elife 2015; 4:e05434.

20. Davies MP, Barraclough DL, Stewart C, Joyce KA, Eccles RM, Barraclough R, Rudland PS, Sibson DR. Expression and splicing of the unfolded protein response gene XBP-1 are significantly associated with clinical outcome of endocrine-treated breast cancer. Int J Cancer. 2008;123:85-8.

21. Adachi Y, Yamamoto K, Okada T, Yoshida H, Harada A, Mori $\mathrm{K}$. ATF6 is a transcription factor specializing in the regulation of quality control proteins in the endoplasmic reticulum. Cell Struct Funct. 2008;33:75-89.

22. Bourougaa K, Naski N, Boularan C, Mlynarczyk C, Candeias MM, Marullo S, Fahraeus R. Endoplasmic reticulum stress induces $\mathrm{G} 2$ cell-cycle arrest via mRNA translation of the p53 isoform p53/47. Mol Cell. 2010;38:78-88.

23. Scheuner D, Song B, McEwen E, Liu C, Laybutt R, Gillespie P, Saunders T, Bonner-Weir S, Kaufman RJ. Translational control is required for the unfolded protein response and in vivo glucose homeostasis. Mol Cell. 2001;7:1165-76.

24. Oyadomari S, Mori M. Roles of CHOP/GADD153 in endoplasmic reticulum stress. Cell Death Differ. 2004;11:381-9.

25. Sano R, Reed JC. ER stress-induced cell death mechanisms. Biochim Biophys Acta. 2013;1833:3460-70.

26. Matsuo K, Gray MJ, Yang DY, Srivastava SA, Tripathi PB, Sonoda LA, Yoo EJ, Dubeau L, Lee AS, Lin YG. The endoplasmic reticulum stress marker, glucose-regulated protein-78 (GRP78) in visceral adipocytes predicts endometrial cancer progression and patient survival. Gynecol Oncol. 2013;128:552-9.

27. Zheng YZ, Cao ZG, Hu X, Shao ZM. The endoplasmic reticulum stress markers GRP78 and CHOP predict disease-free survival and responsiveness to chemotherapy in breast cancer. Breast Cancer Res Treat. 2014;145:349-58.

28. Yasumura RKY, Ochiai R. A comparison of plasma levobupivacaine concentrations following transversus abdominis plane block and rectus sheath block. Anaesthesia. 2016;71:544-9.

29. Trabelsi BCR, Bennasr L, Marzouk SB, Eljebari H, Jebabli N, Sassi MB, Trabelsi S, Maghrebi H. Pharmacokinetics of bupivacaine after bilateral ultrasound-guided transversus abdominis plane block following cesarean delivery under spinal anesthesia. Int J Obstet Anesth 2017;32:17-20.

30. Thanapal MRTM, Tan AJ, Subramaniam T, Tong JM, Palayan K, Rampal S, Gurunathan R. Pre-emptive intraperitoneal local anaesthesia: an effective method in immediate post-operative pain management and metabolic stress response in laparoscopic appendicectomy, a randomized, double-blinded, placebo-controlled study. ANZ J Surg. 2014;84:47-51.

31. Kahokehr AST, Zargar Shoshtari K, Taylor M, Hill AG. Intraperitoneal local anesthetic improves recovery after colon resection: a double-blinded randomized controlled trial. Ann Surg. 2011;254:28-38. 